\title{
Episcleral Venous Tortuosity Indicates Increased Ventricular Filling Pressure in Heart Failure with Reduced Ejection Fraction
}

\section{(1) Şahbender Koç}

Ankara Keçiören Training and Research Hospital, Clinic of Cardiology, Ankara, Turkey

\begin{abstract}
Objectives: In chronic venous hypertension (HT), the adaptation of smooth muscle-poor veins typically occurs with corkscrew-like morphology. The observation of episcleral venous tortuosity (EVT) seems to be a simple and important method for the detection of chronic venous HT using the eye. Whether EVT can provide knowledge about left ventricular (LV) end diastolic pressure via the surrogate marker of lateral ratio between early mitral inflow velocity and mitral annular early diastolic velocity (E/E') in heart failure (HF) with reduced ejection fraction (HFrEF) is unknown.
\end{abstract}

Materials and Methods: The study included 200 cases of HFrEF and 200 control subjects with normal ejection fractions and similar ages $(59.3 \pm 7.6$ and $58.6 \pm 6.8$ years, respectively) and sex distribution. EVT was determined using a simple visual light source. Echocardiographic parameters were measured using accepted methods.

Results: EVT was found in 43 (21.5\%) cases in the HFrEF group and $15(7.5 \%)$ subjects in the control group. In the control group, areas under receiver operating characteristic curves for the LV lateral E/E' (>10.5), right ventricular (RV) lateral E/E' (>5.5), and LV mass index $\left(>115 \mathrm{~g} / \mathrm{m}^{2}\right)$ distinguished subjects with and without EVT $(p<0.05)$. The detection of tortuosity in episcleral veins in the HFrEF group was correlated with the LV lateral E/E' (>15.25), RV E/E' (>12.2), tricuspid annular plane systolic excursion (TAPSE); $<1.45$, LV mass index $\left(>106 \mathrm{~g} / \mathrm{m}^{2}\right)$, atrial fibrillation, and presence of long-term HF.

Conclusion: Tortuosity in episcleral veins in patients with HFrEF can predict the LV lateral E/E' (>15.25), RV E/E' $(>12.2)$, TAPSE $(<1.45)$, and LV mass index $(>106$ $\left.\mathrm{g} / \mathrm{m}^{2}\right)$ with sensitivity $(65.1 \%, 30.2 \%, 74.4 \%$, and $53.5 \%$, respectively) and specificity $(96.8 \%, 97.4 \%, 62.4 \%$, and $77.1 \%$, respectively).

Keywords: Episcleral venous tortuosity, heart failure with reduced ejection fraction, ventricular filling pressure, E/E', TAPSE

Address for Correspondence: Şahbender Koç, Ankara Keçiören Training and Research Hospital, Clinic of Cardiology, Ankara, Turkey e-mail: sahbenderkoc@hotmail.com ORCID: orcid.org/0000-0002-6437-0903

Received: 14.02.2020 Accepted: 12.08.2020

Cite this article as: Koç Ş. Episcleral Venous Tortuosity Indicates Increased Ventricular Filling Pressure in Heart Failure with Reduced Ejection Fraction. EJCM 2020;8(3):113-122.

DOI: $10.32596 /$ jem.galenos.2020.02.08 


\section{Introduction}

Approximately $75 \%$ of the total blood volume is in the venous system, comprised mainly of the small veins and venules $^{(1)}$. Most of the vascular venous system is far from areas that can be observed directly. However, the episcleral veins are visible because of the clarity and transparency of the conjunctiva.

The main venous drainage of the limbus occurs through episcleral veins, and then combines with the discharge from the ophthalmic veins. These veins are then drained into the superior and inferior orbital veins and cross into the jugular venous system ${ }^{(2,3)}$. As direct observation of the vortex veins, which account for the largest portion of venous drainage of the eyes, is difficult, the identification of tortuosity in the episcleral veins seems to be a simply made and important finding.

Systolic and diastolic dysfunctions increase the filling pressure. When the stroke volume is no longer maintained by compensatory mechanisms, such as the Frank-Starling law, the ventricle dilates to maintain end-diastolic pressure and stoke volume. A reduction of cardiac output leads to decreases in systemic and pulmonary vascular function and renal function. Venous pooling increases the venous blood volume and pressure ${ }^{(4)}$, which may affect the episcleral veins visible in the eye.

The contraction and relaxation of smooth muscle cells cause temporary changes in blood flow or pressure, whereas chronic increases in transmural pressure, such as venous hypertension (HT), create vascular re-modelling to normalize the wall stress ${ }^{(5)}$.

In arteries, re-modelling occurs in the form of arterial wall thickening. Adaptation in veins with thin walls and weak smooth muscle typically occurs with corkscrew-like morphology $y^{(6,7)}$.

In heart failure (HF) with reduced ejection fraction (EF) (HFrEF), increased venous pressure may result in dilatation and folding of all body veins at various ratios over the long term ${ }^{(8)}$ The right ventricular (RV) and left ventricular (LV) ratio between early mitral inflow velocity and mitral annular early diastolic velocity (E/E') ratio is correlated with ventricular filling pressure and is simple to measure. LV lateral E/E' ratios $>14$ correlate well with LV end diastolic pressure or pulmonary capillary wedge pressure ${ }^{(9)}$. Among all echo parameters, a lateral E/E' ratio $>10$ was defined as the best marker of diastolic dysfunction, with a detection rate of $86 \%$, superior to the rate of $70 \%$ for transmitral Doppler measures ${ }^{(10)}$.

What clues might episcleral venous tortuosity (EVT), which can be detected on the front segment of the eye with a simple light source by opening the eyelid, give us about E/E', a surrogate parameter for ventricular filling pressure, in patients with $\mathrm{HFrEF}$ ?

\section{Materials and Methods}

\section{Study Inclusion Criteria}

The study included $200 \mathrm{HFrEF}$ cases $(\mathrm{EF} \leq 45 \%)$ and 200 control subjects not diagnosed as HF, with normal EFs ( $\geq 50 \%)$, of similar ages $(59.3 \pm 7.6$ and $58.6 \pm 6.8$ years, respectively) and sex distribution.

\section{Study Exclusion Criteria}

Cases with ocular surface disease; those with infectious and inflammatory diseases, such as conjunctivitis, episcleritis, scleritis, uveitis, keratitis, and pterygium; those who had undergone eye operations; and those who had glaucoma, acne rosacea, keratoconjunctivitis sicca, exophthalmos, or lagophthalmos were not included in the study.

\section{Biomicroscopic Examination to Distinguish Conjunctival and Episcleral Veins}

After visual eye inspection using a simple light source, biomicroscopic examination was performed for each patient. The conjunctiva and tenon veins may be moved manually over the sclera, but the episcleral veins do not move. After the patient's blood pressure was confirmed to be below $140 / 100 \mathrm{mmHg}, 2.5 \%$ phenylephrine was administered as drops to ensure differentiation of the conjunctival and episcleral veins. Cases with 
biomicroscopically detected reduced vein size after 2030 min were included in the conjunctival vein group, and those with no detected reduction were included in the episcleral vein group.

Biomicroscopy was used to check whether the vein could be moved manually, whether blood flow was in the centrifugal flow direction, and whether the flow was pulsatile. Veins that could not be moved manually, those that displayed centrifugal flow, and those without pulsatile flow were accepted as episcleral ${ }^{(11,12)}$. Additionally, the location of an outlet blood flow point about 1-3 mm from the limbus was considered to favor classification into the episcleral vein group. Veins in which pulsatile flow was observed visually and those in which blood flow was not distinguishable biomicroscopically were considered to belong to the episcleral artery group ${ }^{(13)}$ EVT was recorded as present or absent, regardless of whether it was in one or both eyes or whether it occurred together with conjunctival venous tortuosity. Digital photographs of tortuous episcleral veins taken in the best imaging position are provided in Figure 1.

\section{Echocardiographic Data Acquisition}

Echocardiography was performed with a Philips Epic 7 ultrasound system equipped with tissue Doppler technology and a 3.5-MHz transducer, using the QLAB software system. The images were taken after short expiration from apical four-chamber views. Pulse Tissue Doppler Image (TDI) volume samples were recorded from the mitral annulus (lateral side) and tricuspid annulus (free wall side) in parallel with each wall. End-systolic and end-diastolic LV area and volume images were taken from the apical four chambers. The left ventricular ejection fraction (LVEF) was calculated from these data. Mitral and tricuspid inflow patterns were also assessed from apical four-chamber views, and early wave maximal velocities were measured. The RV tricuspid annular plane systolic excursion (TAPSE), $(\mathrm{cm})$ was measured using the M-mode as described previously. The systolic pulmonary

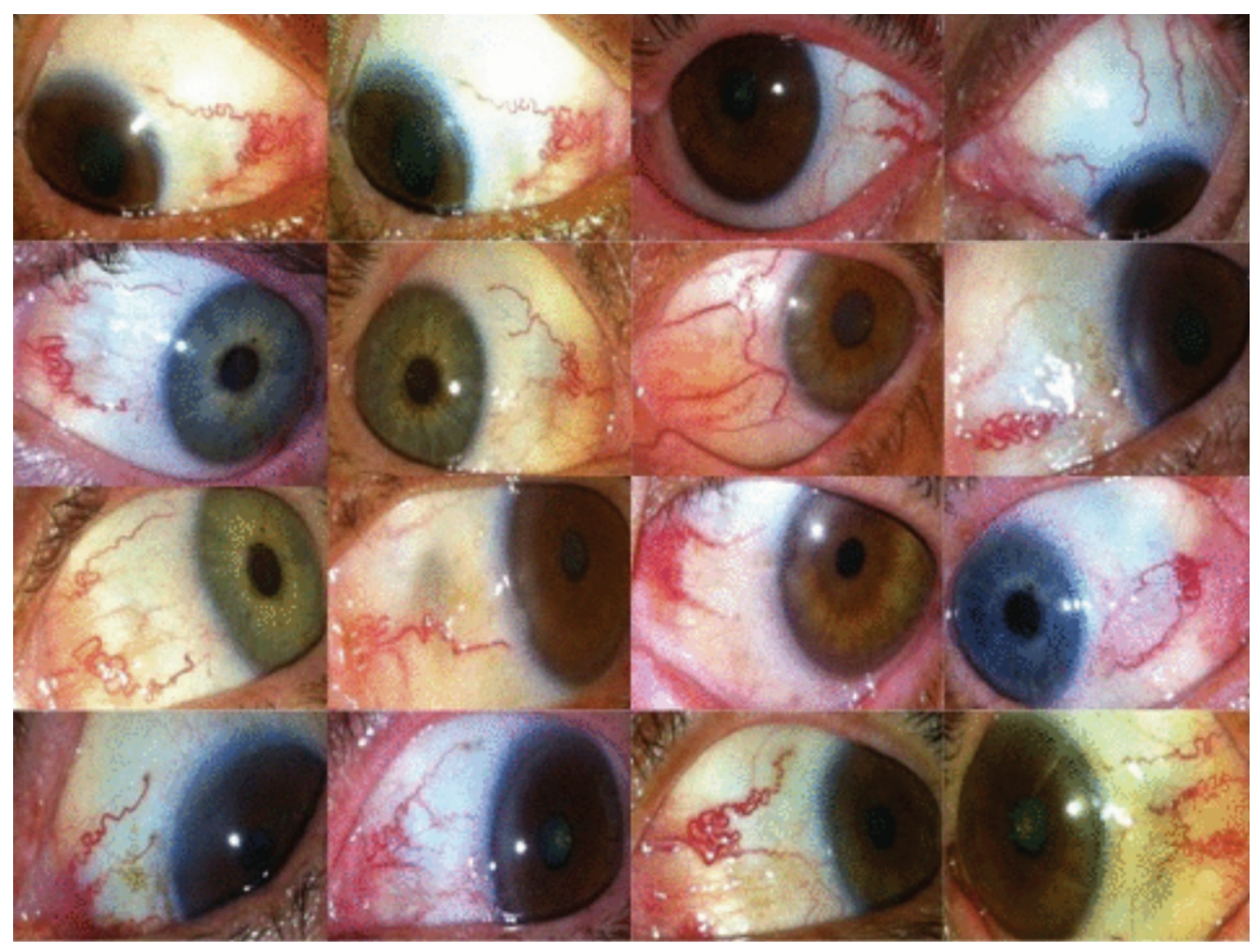

Figure 1. Examples of tortuous episcleral veins. The two photographs in the first line show no change in the episcleral vein as a result of phenylephrine collyre instillation 
artery pressure $(\mathrm{mmHg})$ was calculated using the maximal tricuspid regurgitant (TR) jet.

Early diastole (E') velocities with mitral and tricuspid annuli peak velocities were measured from the lateral wall base. LV E/E', peak TR velocity, differences in the RV E/E' ratio, $\mathrm{LV}$ diastolic diameter $(\mathrm{cm})$, right ventricle diastolic diameter mid $(\mathrm{cm})$, left atrial volume index (LAVI), (mL/ $\mathrm{m}^{2}$ ), left atrial minor $(\mathrm{cm})$, right atrial minor $(\mathrm{cm})$, mitral insufficiency (stage), tricuspid insufficiency (in meters per second), inferior vena cava (IVC) diameter ( $\mathrm{cm}$ ), and IVC collapse $(+/-)$ were also measured. LV Hypertrophy was assessed using the echocardiographically determined LV mass index (LVMI) $\left(\mathrm{g} / \mathrm{m}^{2}\right)$. The LV mass was calculated using the cubed formula and converted to the LVMI. All measurements were performed as described in relevant guidelines $^{(14,15)}$. All values were the means of three measurements. The intra-class correlation coefficient was $0.90(0.88-0.92)$ for all measurements.

Informed consent was obtained from all participants. The study was conducted in accordance with the Declaration of Helsinki. Ethics committee approval was received for this study from Ankara Keçiören Training and Research Hospital (decision no: 1101, date: 09.03.2016).

\section{Statistical Analysis}

Data were analyzed using SPSS (ver. 11.5 for Windows; SPSS Inc., Chicago, IL, USA). The normality of distribution of continuous variables was assessed using the Kolmogorov-Smirnov test. Data were presented as mean \pm standard deviation or median (ranges). Mean differences between groups were assessed using the Student's t test, and medians were compared using the Mann-Whitney U test. Nominal data were analyzed using the Pearson's chisquared or Fisher's exact test. The optimal cut-off point for each clinical measurement for the discrimination of cases with and without ocular findings was determined by receiver operating characteristic (ROC) analyses. Areas under the curves were calculated to determine the maximum sum of sensitivity and specificity for significant findings. Sensitivity, specificity, positive predictive values (PPVs), and negative predictive values (NPVs) were also calculated to determine the best cut-off point for each clinical measurement. The best predictor(s) for the discrimination of cases with and without ocular findings was determined by multiple logistic regression analyses using the backward likelihood ratio procedure. Adjusted Odds ratios (ORs), 95\% confidence intervals (CIs), and Wald statistics were also calculated. All variables with $\mathrm{p}<0.25$ in univariable analysis were entered into the multivariable model, along with all variables of known clinical importance. $P$ values $<0.05$ were considered to be significant.

\section{Results}

The average ages in the two groups were $59.3 \pm 7.6$ and $58.6 \pm 6.8$ years $(\mathrm{p}=0.628)$. No difference was observed between the groups in the presence of HT, diabetes mellitus (DM), or smoking or in the glucose or hemoglobin concentration. The creatinine and low-density lipoprotein cholesterol levels, echocardiographic values, and presence of atrial fibrillation (AF) and pretibial edema differed between the groups. The mean duration of HF in the HFrEF group was 4 years (range, 1-8 years). The mean stage, according to the New York Heart Association (NYHA) classification, was 2 (range, 1-4). The main characteristics and echocardiographic data for the HFrEF and control groups are summarized in Table 1.

EVT was observed in $43(21.5 \%)$ persons in the HFrEF group [right eye, $n=23$ patients; left eye, $n=20$ (both eyes, $\mathrm{n}=8)$ ] and $15(7.5 \%)$ persons in the control group [right eye, $n=7$; left eye, $n=8$ (both eyes, $n=4$ ); $p<0.001$ ] Twenty-three $(39 \%)$ female and $35(60 \%)$ male subjects had EVT $(p=0.817)$. No difference was observed in systolic or diastolic blood pressure between the groups with $(n=58)$ and without $(n=342)$ EVT $(p=0.419$ and $\mathrm{p}=0.728$, respectively).

In the HFrEF group, the frequency of HT and median TAPSE level were significantly lower and the median HF duration, median RV E/E', LV E/E', LVMI and AF frequency were significantly higher in those with EVT than in those without EVT (all $p<0.05$ ). The characteristics 
Table 1. Main characteristics and ecocardiographic measurements of heart failure and control groups

\begin{tabular}{|c|c|c|c|}
\hline Main characteristics & $\begin{array}{l}\text { HFrEF patients } \\
(n=200)\end{array}$ & $\begin{array}{l}\text { Control patients } \\
(n=200)\end{array}$ & p value \\
\hline Age (year) (n) & $59.3 \pm 7.6$ & $58.6 \pm 6.8$ & 0.628 \\
\hline Gender (male/female) (n) & $85 / 115$ & $90 / 110$ & 0.615 \\
\hline Systolic BP (mmHg) & $128 \pm 19$ & $124 \pm 16$ & 0.084 \\
\hline Diastolic BP (mmHg) & $75 \pm 14$ & $70 \pm 12$ & 0.349 \\
\hline Heart rate $(\mathrm{bpm})$ & $69(40-130)$ & $68(45-130)$ & 0.01 \\
\hline Body mass index $\left(\mathrm{kg} / \mathrm{m}^{2}\right)$ & $26.6(18-34)$ & $27.03(18-34)$ & 0.24 \\
\hline Hypertension presence(n) & $92(52 \%)$ & $85(48 \%)$ & 0.481 \\
\hline Tobacco use (n) & $79(48.5 \%)$ & $84(51.5 \%)$ & 0.611 \\
\hline Diabetes (n) & $49(47.6 \%)$ & $54(52.4 \%)$ & 0.567 \\
\hline LDL Cholesterol (mg/dL) & $111(56-243)$ & $89(64-216)$ & $<0.001$ \\
\hline Glucose (mg/dL) & $91(64-254)$ & $87(62-229)$ & 0.568 \\
\hline Hemoglobin (gr/dL) & $12(6.5-15)$ & $12.4(6.9-19)$ & 0.704 \\
\hline Creatinine (mg/dL) & $1.0(0.5-1.8)$ & $0.79(0.4-1.8)$ & $<0.001$ \\
\hline \multicolumn{4}{|l|}{ Echocardiography parameters } \\
\hline Ejection fraction (\%) & $35(20-45)$ & $63(50-66)$ & $<0.001$ \\
\hline LVDD (cm) & $6.2(4.8-7.2)$ & $5.6(4.5-6.4)$ & $<0.001$ \\
\hline RVDD (mid) (cm) & $4.4(3.4-5.4)$ & $3.5(2.8-4.1)$ & $<0.001$ \\
\hline LV mass index $\left(\mathrm{g} / \mathrm{m}^{2}\right)$ & $91(56-118)$ & $102(78-132)$ & 0.001 \\
\hline LA minor diameter(cm) & $4.1(3.0-5.1)$ & $3.4(2.8-4.0)$ & $<0.001$ \\
\hline LAVI $\left(\mathrm{mL} / \mathrm{m}^{2}\right)$ & $32(27-47)$ & $21(15-36)$ & $<0.001$ \\
\hline RA minor diameter $(\mathrm{cm})$ & $4.6(3.4-5.8)$ & $3.3(2.8-4.0)$ & $<0.001$ \\
\hline RV E/E' & $10.1(5.4-22)$ & $5.2(3-9.2)$ & $<0.001$ \\
\hline LV E/E' & $11.3(5.3-21.4)$ & $8.2(5.3-14.2)$ & $<0.001$ \\
\hline Pulmonary artery diameter $(\mathrm{cm})$ & $2.1(1.7-2.6)$ & $1.8(1.3-2.5)$ & $<0.001$ \\
\hline SPAB $(\mathrm{mmHg})$ & $50(30-74)$ & $25(22-35)$ & $<0.001$ \\
\hline IVC diameter (cm) & $2(1.7-2.4)$ & $1.8(1.5-2.4)$ & $<0.001$ \\
\hline IVC collapse $\leq \% 50(+/-)$ & $70 / 130$ & $25 / 175$ & $<0.001$ \\
\hline TAPSE $(\mathrm{cm} / \mathrm{s})$ & $1.5(1-2.4)$ & $1.9(1.5-2.5)$ & $<0.001$ \\
\hline Tricuspid insufficiency (m/s) & $3.2(2.9-4.2)$ & $2.6(2-3.2)$ & $<0.001$ \\
\hline Mitral insufficiency $(\geq 2)(+/-)$ & $171 / 29$ & $14 / 186$ & $<0.001$ \\
\hline \multicolumn{4}{|l|}{ Characteristics } \\
\hline QRS duration (ms) & $140(110-170)$ & $100(70-120)$ & $<0.001$ \\
\hline AF presence (+/-) & $34 / 166$ & $-/ 200$ & $<0.001$ \\
\hline Coronary AD presence(n) & $93(49.2 \%)$ & $96(50.8 \%)$ & 0.764 \\
\hline PTE presence (+/-) & $26 / 174$ & $11 / 189$ & 0.007 \\
\hline ACEI usage (+/-) & $138 / 62$ & $135 / 65$ & 0.83 \\
\hline Betablocker usage (+/-) & $151 / 49$ & $42 / 158$ & $<0.001$ \\
\hline Coumadin or NOAC usage (+/-) & $28 / 172$ & $-/ 200$ & $<0.001$ \\
\hline Antilipidemic usage (+/-) & $20 / 180$ & $30 / 170$ & 0.173 \\
\hline Diuretic usage (+/-) & $134 / 66$ & $3 / 197$ & $<0.001$ \\
\hline Acetylsalicylic usage (+/-) & $117 / 83$ & $143 / 57$ & 0.009 \\
\hline
\end{tabular}

HFrEF: Heart failure reduced ejection fraction, Bpm: Beat per minute, LVDD: Left ventricle diastolic diameter, RVDD: Right ventricle diastolic diameter, LH: Left ventricle hypertrophy, LA: Left atrium, RA: Right atrium, RV: Right ventricle, SPAB: Systolic pulmonary artery pressure, LAVI: Left atrium volume index, IVC: Inferior vena cava, AF: Atrial fibrillation, Coronary AD: Coronary artery disease, PTE: Pretibial edema, ACEI: Angiotensin-converting enzyme inhibitor, NOAC: New oral anticoagulant, LDL: Low density lipoprotein, $n$ : Number, BP: Blood pressure, E/E': Ratio between early mitral inflow velocity and mitral annular early diastolic velocity, TAPSE: Tricuspid annular plane systolic excursion 
Table 2. Demographic and clinical characteristics of subjects in the groups with and without episcleral venous tortuosity in the heart failure group

\begin{tabular}{|c|c|c|c|}
\hline \multirow[b]{2}{*}{ Variables } & \multicolumn{2}{|c|}{ Episcleral venous tortuosity } & \multirow{2}{*}{$\begin{array}{l}p \\
\text { value }\end{array}$} \\
\hline & $\begin{array}{l}\text { No } \\
(n=157)\end{array}$ & $\begin{array}{l}\text { Yes } \\
(n=43)\end{array}$ & \\
\hline Age (years) & $59.4 \pm 8.0$ & $59.2 \pm 7.3$ & 0.859 \\
\hline Female, n (\%) & $52(33.1 \%)$ & $14(32.6 \%)$ & 0.945 \\
\hline HT, n (\%) & $78(49.7 \%)$ & $14(32.6 \%)$ & 0.046 \\
\hline Smoking, n (\%) & $60(38.2 \%)$ & $19(44.2 \%)$ & 0.478 \\
\hline $\mathrm{DM}, \mathrm{n}(\%)$ & $43(27.4 \%)$ & $6(14.0 \%)$ & 0.070 \\
\hline EF \% (min-max) & $35(20-45)$ & $35(20-45)$ & 0.676 \\
\hline NYHA (stage) & $2(1-4)$ & $2(2-4)$ & 0.173 \\
\hline $\begin{array}{l}\text { HFrEF duration } \\
\text { (years) }\end{array}$ & $3(1-8)$ & $5(2-8)$ & $<0.001$ \\
\hline QRS ms & $140(120-170)$ & $135(110-160)$ & 0.594 \\
\hline Ischemia, n (\%) & $73(46.5 \%)$ & $20(46.5 \%)$ & 0.999 \\
\hline E/E' (RV) ratio & $10(5-17.8)$ & $10.1(5-22)$ & 0.003 \\
\hline E/E' (LV) ratio & $11.2(5-18)$ & $16(7-22)$ & $<0.001$ \\
\hline TAPSE (cm) & $1.5(1-2.4)$ & $1.3(1.0-1.9)$ & $<0.001$ \\
\hline LV mass index $\left(g / m^{2}\right)$ & $93(74-110)$ & $106(96-118)$ & $<0.001$ \\
\hline LA minor $(\mathrm{cm})$ & $3.9(3-4.9)$ & $4.08(3.2-5.1)$ & 0.015 \\
\hline LAVI $\left(m L / m^{2}\right)$ & $32.5(24-42)$ & $33.4(25-48)$ & 0.038 \\
\hline LVDD (cm) & $6.2(4.8-7.2)$ & $6.2(4.8-7.2)$ & 0.818 \\
\hline RVD mid (cm) & $4.4(3.4-5.4)$ & $4.4(3.4-5.4)$ & 0.712 \\
\hline LA minor $(\mathrm{cm})$ & $5.2(2.8-6.5)$ & $5.2(3.2-6.5)$ & 0.767 \\
\hline MI (stage) & $2(0-4)$ & $2(0-4)$ & 0.280 \\
\hline $\mathrm{TI}(\mathrm{m} / \mathrm{s})$ & $3.2(2.6-4.0)$ & $3.2(2.6-4.0)$ & 0.542 \\
\hline SPAB (mmHg) & $50(30-74)$ & $50(30-74)$ & 0.561 \\
\hline $\mathrm{P}_{\text {art }}$ diameter $(\mathrm{cm})$ & $2.1(1.7-2.6)$ & $2.1(1.7-2.6)$ & 0.433 \\
\hline $\mathrm{RA}_{\min }$ diameter $(\mathrm{cm})$ & $3.9(3.4-4.8)$ & $4.09(3.6-4.8)$ & 0.025 \\
\hline IVC diameter $(\mathrm{cm})$ & $2.0(1.7-2.4)$ & $2.0(1.7-2.4)$ & 0.770 \\
\hline IVC collapse, n (\%) & $89(56.7 \%)$ & $22(51.2 \%)$ & 0.518 \\
\hline $\mathrm{AF}(+/-)$ & $5(3.2 \%)$ & $29(67.4 \%)$ & $<0.001$ \\
\hline PTE (+/-) & $19(12.1 \%)$ & $8(18.6 \%)$ & 0.269 \\
\hline
\end{tabular}

EF: Ejection fraction, TAPSE: Tricuspid annular plane systolic excursion, LVDD: Left ventricle diastolic diameter, RVDD: Right ventricle diastolic diameter, LV: Left ventricle, RV: Right ventricle, LA: Left atrium, LAVI: Left atrium volume index, MI: Mitral insufficiency, TI: Tricuspit insufficiency, SPAB: Systolic pulmonary artery pressure, Part: Pulmonary artery, $R A_{\text {min }}:$ Right atrium minor, IVC: Inferior vena cava, AF: Atrial fibrillation, PTE: Pretibial edema, DM: Diabetes mellitus, NYHA: New York Heart Association, min: Minimum, max: Maximum, n: Number, HT: Hypertension, HFrEF: Heart failure reduced ejection fraction, E/E': Ratio between early mitral inflow velocity and mitral annular early diastolic velocity

Significant changes are shown as bold of subjects in the HFrEF group with and without EVT are shown in Table 2.

The factors best distinguishing subjects with and without EVT in the HFrEF group were the LV lat $\mathrm{E} / \mathrm{E}$, presence of $\mathrm{AF}$, and $\mathrm{HF}$ duration $(\mathrm{p}<0.01)$. After adjustment according to other possible risk factors, LV E/E' $>15.25$ increased the probability of EVT 25 times (95\% CI, 6.677-97,145; $<<0.001$ ), the presence of $\mathrm{AF}$ increased the probability of EVT 23 times (95\% CI, 6.32089.352; $<<0.001)$, and lengthy HF duration significantly increased the probability of EVT $(\mathrm{OR}=1.503 ; 95 \% \mathrm{CI}$, 1.118-2.020; $\mathrm{p}=0.007)$.

Areas below ROC curves were significant for the RV E/E',LVE/E', TAPSE, and LVMI in distinguishing subjects with and without EVT in the HFrEF group $(p<0.05)$. The best cut-off points were: $>12.2,>15.25,<1.45$, and $>106$

Table 3. Area below the ROC curve and 95\% confidence intervals for clinical measurements in distinguishing between the groups with and without episcleral venous tortuosity in the HFrEF group

\begin{tabular}{|c|c|c|c|}
\hline Variables & AUC & $\begin{array}{l}\% 95 \text { Confidence } \\
\text { intervals }\end{array}$ & $p$ value \\
\hline E/E' (LV) ratio & 0.845 & $0.765-0.925$ & $<0.001$ \\
\hline E/E' (RV) ratio & 0.657 & $0.542-0.752$ & 0.003 \\
\hline TAPSE (cm) & 0.720 & $0.638-0.802$ & $<0.001$ \\
\hline LV mass index $\left(\mathrm{g} / \mathrm{m}^{2}\right)$ & 0.675 & $0.578-0.771$ & $<0.001$ \\
\hline LA minor $(\mathrm{cm})$ & 0.575 & $0.420-0.609$ & 0.067 \\
\hline LAVI $\left(\mathrm{mL} / \mathrm{m}^{2}\right)$ & 0.545 & $0.415-0.685$ & 0.071 \\
\hline LVDD (cm) & 0.511 & $0.412-0.611$ & 0.820 \\
\hline $\mathrm{RVDD}_{\text {mid }}(\mathrm{cm})$ & 0.518 & $0.420-0.617$ & 0.712 \\
\hline $\mathrm{TI}(\mathrm{m} / \mathrm{s})$ & 0.530 & $0.434-0.625$ & 0.550 \\
\hline SPAB $(\mathrm{mmHg})$ & 0.529 & $0.432-0.625$ & 0.566 \\
\hline $\mathrm{P}_{\text {art }}$ diameter $(\mathrm{cm})$ & 0.539 & $0.441-0.636$ & 0.439 \\
\hline $\mathrm{RA}_{\min }(\mathrm{cm})$ & 0.512 & $0.414-0.610$ & 0.808 \\
\hline IVC diameter (cm) & 0.514 & $0.420-0.608$ & 0.774 \\
\hline
\end{tabular}

AUC: Area under the curve, TAPSE: Tricuspid annular plane systolic excursion, LV: Left ventricle, LVDD: Left ventricle diastolic diameter, RVDD: Right ventricle diastolic diameter, LA: Left atrium, LAVI: Left atrium volume index, TI: Tricuspid insufficiency, SPAB: Systolic pulmonary artery pressure, $P_{\text {art }}$ : Pulmonary artery diameter RA: Right atrium, IVC: Inferior vena cava, HFrEF: Heart failure with reduced ejection fraction, ROC: Receiver operating characteristic, E/E': Ratio between early mitral inflow velocity and mitral annular early diastolic velocity

Significant changes are shown as bold 
$\mathrm{g} / \mathrm{m}^{2}$, respectively (sensitivity, $30.2 \%, 65.1 \%, 74.4 \%$, and $53.5 \%$; specificity, $97.4 \%, 96.8 \%, 62.4 \%$, and $77.1 \%$; PPV, 76.5\%, 84.8\%, 35.2\%, and 39.0\%; and NPV, 83.5\%, $91.0 \%, 89.9 \%$, and $85.8 \%$, respectively). Data for the other characteristics are provided in Table 3.

In the control group, the tobacco usage frequency, DM frequency, median RV E/E', LV E/E', LVMI, and IVC collapse frequency were significantly higher in those with EVT than in those without EVT $(p<0.05)$. The characteristics of subjects with and without EVT in the control group are shown in Table 4.

The factors best distinguishing subjects with and without EVT in the control group were the LV E/E', LVMI $>115 \mathrm{~g} / \mathrm{m}^{2}$, and IVC collapse. ORs were determined for these factors. After adjustment according to other possible risk factors, the probability of EVT was increased significantly with an increased LV E/E' $(\mathrm{OR}=3.2 ; 95 \% \mathrm{CI}, 1.522-6.789$; Wald $=9.369 ; \mathrm{p}=0.002)$ LVMI $>115 \mathrm{~g} / \mathrm{m}^{2}(\mathrm{OR}=45.542 ; 95 \%$ CI, 3.631-571.161; Wald $=8.758 ; \mathrm{p}=0.003$ ), and presence of IVC collapse $(\mathrm{OR}=11.323 ; 95 \%$ CI， 1.220-105.062; Wald $=4.559$; $\mathrm{p}=0.033)$.

Areas below ROC curves were significant for the RV E/E' (0.831; 95\% CI, 0.672-0.989; p<0.001), LV E/E (0.864; 95\% CI, 0.730-0.998; $<<0.001)$, and LVMI $>115 \mathrm{~g} / \mathrm{m}^{2}(0.910 ; 95 \% \mathrm{CI}, 0.817$ to $>1.000 ; \mathrm{p}<0.001)$. The best cut-off points for these indicators were $>5.5$, $>10.5$, and $>115 \mathrm{~g} / \mathrm{m}^{2}$, respectively (sensitivity, all 73.3\%; specificity, 94.6\%, 100.0\%, and 97.8\%; PPV, $52.4 \%, 100.0 \%$, and $73.3 \%$; and NPV, $97.8 \%, 97.9 \%$, and $97.8 \%$, respectively).

\section{Discussion}

In this study, common findings in patients with EVT in both groups were increased LVE/E', RV E/E', and the LVMI. In the HFrEF group, EVT was associated with LV E/E'>15.25, RV E/E'>12.2, TAPSE $<1.45 \mathrm{~cm}$, and LVMI $>106 \mathrm{~g} / \mathrm{m}^{2}$ (in order of decreasing sensitivity and specificity), presence of AF, and longer HF duration.

\section{Right Ventricular E/E' Ratio}

The mean systemic filling pressure (PMSF) is the pressure in the vascular system during circulatory arrest. Venous return is determined by the pressure gradient

Table 4. Demographic and clinical characteristics of subjects in the groups with and without episcleral venous tortuosity in the control group

\begin{tabular}{|c|c|c|c|}
\hline \multirow{2}{*}{ Variables } & \multicolumn{2}{|c|}{$\begin{array}{l}\text { Episcleral venous } \\
\text { tortuosity }\end{array}$} & \multirow{2}{*}{$p$ value } \\
\hline & $\begin{array}{l}\text { No } \\
(n=185)\end{array}$ & $\begin{array}{l}\text { Yes } \\
(n=15)\end{array}$ & \\
\hline Age (years) & $57.7 \pm 7.6$ & $59.5 \pm 6.0$ & 0.373 \\
\hline Female, n (\%) & $79(42.7 \%)$ & $10(66.7 \%)$ & 0.072 \\
\hline HT, n (\%) & $76(41.1 \%)$ & $9(60.0 \%)$ & 0.154 \\
\hline Tobacco use, $\mathbf{n}(\%)$ & $73(39.5 \%)$ & $11(73.3 \%)$ & 0.011 \\
\hline DM, n (\%) & $45(24.3 \%)$ & $9(60.0 \%)$ & 0.005 \\
\hline $\mathrm{EF}$ (min-max) & $63(50-66)$ & $65(60-65)$ & 0.110 \\
\hline QRS (ms) & $100(70-120)$ & $100(80-120)$ & 0.676 \\
\hline Ischemia, n (\%) & $87(47.0 \%)$ & $9(60.0 \%)$ & 0.333 \\
\hline $\mathrm{E} / \mathrm{E}^{\prime}(\mathrm{RV})$ ratio & $5.2(3-6)$ & $7(3-9)$ & $<0.001$ \\
\hline E/E' (LV) ratio & $8.1(5-10)$ & $11.2(6-14)$ & $<0.001$ \\
\hline TAPSE (cm) (min-max) & $1.9(1.5-2.5)$ & $1.9(1.7-2.4)$ & 0.993 \\
\hline LV mass index $\left(\mathrm{g} / \mathrm{m}^{2}\right)$ & $102(78-132)$ & $115(96-132)$ & $<0.001$ \\
\hline LVDD (cm) (min-max) & $5.6(4.5-6.4)$ & $5.6(4.8-6.4)$ & 0.998 \\
\hline $\mathrm{RVD}_{\text {mid }}$ diameter $(\mathrm{cm})$ & $3.5(2.8-4.2)$ & $3.5(2.9-4.1)$ & 0.680 \\
\hline LA minor $(\mathrm{cm})$ & $3.6(2.8-4.1)$ & $3.4(2.8-4.1)$ & 0.197 \\
\hline LAVI $\left(\mathrm{mL} / \mathrm{m}^{2}\right)$ & $21.8(14-29)$ & $22.1(12-32)$ & 0.154 \\
\hline MI (grade) & $0(0-1)$ & $0(0-1)$ & 0.319 \\
\hline $\mathrm{TI}(\mathrm{m} / \mathrm{s})(\min -\mathrm{max})$ & $2.6(2.3-2.6)$ & $2.5(2.3-2.6)$ & 0.568 \\
\hline SPAB $(\mathrm{mmHg})$ & $25(22-35)$ & $25(22-35)$ & 0.106 \\
\hline $\mathrm{P}_{\text {art }}$ diameter $(\mathrm{cm})$ & $1.8(1.5-2.5)$ & $1.8(1.3-1.8)$ & 0.079 \\
\hline RA minor diameter $(\mathrm{cm})$ & $3.3(2.8-4.0)$ & $3.3(2.8-3.7)$ & 0.968 \\
\hline IVC diameter $(\mathrm{cm})$ & $1.8(1.5-2.4)$ & $1.8(1.5-2.2)$ & 0.586 \\
\hline IVC collapse (+/-) & $21(11.4 \%)$ & $7(46.7 \%)$ & $<0.001$ \\
\hline $\mathrm{AF}(+/-)$ & - & - & - \\
\hline PTE (+/-) & $10(\% 5.4)$ & $1(\% 6.7)$ & 0.586 \\
\hline
\end{tabular}

HT: Hypertension, DM: Diabetes mellitus, EF: Ejection fraction, LV: Left ventricle, $L V D D$ : Left ventricle diastolic diameter, RVDD: Right ventricle diastolic diameter, LA: Left atrium, LAVI: Left atrium volume index, RA: Right atrium, MI: Mitral insufficiency, TI: Tricuspid insufficiency, SPAB: Systolic pulmonary artery pressure, $P_{\text {art }}$ Pulmonary artery, IVC: Inferior vena cava, AF: Atrial fibrillation, PTE: Pretibial edema, RV: Right ventricle, E/E': Ratio between early mitral inflow velocity and mitral annular early diastolic velocity, TAPSE: Tricuspid annular plane systolic excursion Significant changes are shown as bold 
between the PMSF and right atrial pressure. The RV $\mathrm{E} / \mathrm{E}$ ' ratio is related closely to the RV filling pressures. Irrespective of RV systolic function, $\mathrm{RV} \mathrm{E} / \mathrm{E}$ ' ratios $>6$ have been found to have a sensitivity of $79 \%$ and a specificity of $73 \%$ for the mean right atrial pressure $\geq 10 \mathrm{~mm} \mathrm{Hg}{ }^{(16)}$. Right atrial pressure is approximately $0 \mathrm{mmHg}$, and an increase of $1 \mathrm{mmHg}$ reduces venous return by $14 \%{ }^{(17)}$.

\section{Left Ventricular E/E' Ratio}

LV E/E' ratio $>10$ reflects decreased ventricular filling (elevated LV filling pressure corresponding to a mean post capillary wedge pressure $>15 \mathrm{~mm} \mathrm{Hg}$ ), with a sensitivity of $97 \%$ and a specificity of $78 \%{ }^{(18)}$. In the case of LV E/E' $>12$, dilated cardiomyopathies with similar systolic function were found to be more symptomatic ${ }^{(19)}$. In our study, the NYHA stage and pretibial edema did not differ between patients with and without EVT in the HFrEF group. The frequency of AF was significantly higher in patients with EVT. Increased LV end diastolic pressure increases AF formation ${ }^{(20)}$. LV E/E' $>15$ has independent predictive value for cardiac mortality and $\mathrm{HF}^{(21)}$. It has also been reported to be a predictor of LV dilatation after infarction ${ }^{(22)}$.

\section{TAPSE}

The prevalence of RV systolic dysfunction increases with decreasing LVEF. In hypertensive HF, 53\% RV systolic dysfunction was found with TAPSE ${ }^{(23,24)}$. Decreased TAPSE was found to be an independent predictor of cardiovascular death in the general population ${ }^{(25)}$. In HFrEF and HFpEF, cardiac risk increases by two to three times in patients with decreased TAPSE ${ }^{(26)}$. In one study, the sensitivity and specificity of TAPSE $\leq 1.9 \mathrm{~cm}$ and $\mathrm{E} / \mathrm{E}^{\prime} \geq 10.7$ were found to be $66 \%$ and $77 \%$, and $66 \%$ and $62 \%$, respectively, for the prediction of weak 6-m walking test performance ${ }^{(27)}$. In our study, the sensitivity of TAPSE $<1.45 \mathrm{~cm}$ in the detection of EVT in patients with HFrEF was $74 \%$.

\section{Left Ventricular Wall Thickness}

In the HFrEF group, EVT was detected in cases in which LV wall thickness was lesser, and the LV and RV filling parameter $\left(E / E^{\prime}\right)$ values were greater than in the control group (cut-offs, LV E/E'>10.5, RV E/E'>5.5, and LVMI $>115 \mathrm{~g} / \mathrm{m}^{2}$ ). These findings suggest that in addition to the relatively low filling pressures, a greater LVMI increase was associated with the emergence of EVT in the control group.

\section{Left Ventricular Mass Index}

In the HFrEF group, EVT was detected in cases in which LV wall thickness was lesser, and the LV and RV filling parameter $\left(\mathrm{E} / \mathrm{E}^{\prime}\right)$ values were greater than in the control group (cut-offs, LV E/E' >10.5, RV E/E' >5.5, and LVMI $>115 \mathrm{~g} / \mathrm{m}^{2}$ ). These findings suggest that in addition to the relatively low filling pressures, a greater LVMI increase was associated with the emergence of EVT in the control group. According to LaPlace's law, wall thickness increases in response to pressure overload in HT. The detection of EVT in patients with lower in the HFrEF group compared to those in the control group (LV mass, $106 \mathrm{vs} 115 \mathrm{~g} / \mathrm{m}^{2}$ ) may be due to the decrease in time after the increase in wall thickness as a result of chronic pressure increase $^{(28)}$.

\section{Left Atrial Volume Index}

An increase in left atrial diameter and LAVI suggest chronic severe LV filling characteristics. An increase in LV mass may be related to myocardial fibrosis and myocardial structural changes leading to HF. Among subjects in the HFrEF group with EVT ( $\mathrm{n}=43$ ), AF was present in 29 (67.4\%) patients, whereas it was present in five $(3.2 \%)$ patients without EVT $(\mathrm{p}<0.001)^{(29)}$. This finding reinforces the idea that an increase in LV end diastolic pressure may be an additive factor in the pathogenesis of EVT.

Whereas cigarette smoking and DM seemed to be effective predictors of the presence of tortuosity in the control group, HT was a more frequent indicator in the HFrEF group. HT-dependent wall stiffness can increase LAVI by increasing LV end-diastolic pressures ${ }^{(30)}$. Negative effects of tobacco and DM on the endothelium may contribute to tortuosity ${ }^{(31)}$. 


\section{Vessel Wall Stress and Extracellular Matrix}

As the volume is returned to the systemic circulation by the heart, the returning volume is equal to the stroke volume ${ }^{(32)}$. The volume stretching the vessel wall is called the stress volume. It accounts for $25-30 \%$ of the total blood volume in circulation with minimal sympathetic tone ${ }^{(33)}$. Vessel wall stress is the ratio of the transmural pressure difference and the inner wall diameter multiplied by the wall thickness. As the diameter increases and the thickness decreases during vasodilatation, circular tension stress is greater than vasoconstriction status ${ }^{(34)}$.

A chronic increase in venous pressure was determined to be sufficient for venous re-modelling by experimental venous ligation. Hydrostatic pressure and wall stress were increased proximal to the ligation, and wide tortuous vein development was observed after 2 days $^{(35)}$. In varicose vein re-modelling, changes in the extracellular matrix are the main factor and ensure increased essential rigidity to resist the chronic increase in wall stress ${ }^{(36)}$. Adaptation in smooth muscle cells and activities of matrix metalloproteinase (MMP) also change according to the duration and level of tension in the veins. MMP also plays a leading role in cardiac re-modelling ${ }^{(37)}$. MMP-9 upregulation is the common finding of terminal $\mathrm{HF}^{(38)}$. Similarly, MMP-9 activity was increased in human varicose veins and in rat veins with excess transmural pressure ${ }^{(39)}$.

\section{Study Limitations}

As the differentiation of episcleral and arterial veins was performed using a method based on commonly known observations, precision may not have been attained in some patients. If the interrogation angle is $>20^{\circ}$ on TDIs, the velocity may be less measured than exact values. The fact that episcleral vessel diameters could not be measured is also a limitation.

\section{Conclusion}

The presence of tortuosity in episcleral veins in patients with HFrEF seems to be correlated with RV lateral E/E'
$(>12.2)$, LV lateral E/E' $(>15.25)$, TAPSE $(<1.45 \mathrm{~cm})$, LVMI $\left(>106 \mathrm{~g} / \mathrm{m}^{2}\right), \mathrm{AF}$, and the duration of long-term HF.

Acknowledgments: I would like to thank clinical nurses for their contributions to the study.

\section{Ethics}

Ethics Committee Approval: The study was conducted in accordance with the Declaration of Helsinki. Ethics committee approval was received for this study from Ankara Keçiören Training and Research Hospital (decision no: 1101, date: 09.03.2016).

Informed Consent: Informed consent was obtained from all participants.

Peer-review: Externally peer-reviewed.

Financial Disclosure: The author declared that this study received no financial support.

\section{References}

1. Maas JJ. Mean systemic filling pressure: its measurement and meaning. Neth J Crit 2015;19:6-11.

2. David DT, Tasman W, Jaeger EA. Clinical Ophtalmology. Lippincott Raven,1996.http://80.36.73.149/almacen/medicina/oftalmologia/ enciclopedias/duane/pages/v4/v4c023.

3. Kiel JW. The Ocular Circulation. Colloquium Series on Integrated Systems Physiology: From Molecule to Function. Morgan Claypool Publishers 2011;3:1-81.

4. Klabunde RE. Cardiovascular Pharmacology Concepts Pathophysiology of HeartFailure 04/19/07 https://www.cvpharmacology.com/clinicaltopics/ heart failure2.

5. Beebe-Dimmer JL, Pfeifer JR, Engle JS, Schottenfeld D. The epidemiology of chronic venous insufficiency and varicose veins. Ann Epidemiol $2005 ; 15: 175-84$

6. Wali MA, Eid RA. Changes of elastic and collagen fibers in varicose veins. Int Angiol 2002;21:337-43.

7. Somers P, Knaapen M. The histopathology of varicose vein disease. Angiology 2006;57:546-55.

8. Mäkivaara LA, Ahti TM, Luukkaala T, Hakama M, Laurikka JO. The risk of congestive heart failure is increased in persons with varicose veins. Int Angiol 2009;28:452-7.

9. Ommen SR, Nishimura RA, Appleton CP, et al. Clinical utility of Doppler echocardiography and tissue Doppler imaging in the estimation of left ventricular filling pressures: A comparative simultaneous Dopplercatheterization study. Circulation 2000;102:1788-94.

10. Kasner M, Westermann D, Steendijk P, et al. Utility of Doppler echocardiography and tissue Doppler imaging in the estimation of diastolic 
function in heart failure with normal ejection fraction: a comparative doppler-conductance catheterization study. Circulation 2007;116: 637-47.

11. Probst LE, Tsai JH, Goodman G. Ophthalmology: Clinical and Surgical Principles. SLACK Incorporated, 2012:202.

12. Meyer PA. Patterns of Blood Flow in Episcleral Vessels Studied by LowDose Fluorescein Videoangiography. Eye (Lond) 1988;2:533-46.

13. Meyer PA. The Circulation of the Human Limbus. Eye (Lond) 1989;3:1217.

14. Rudski LG, Lai WW, Afilalo J, et al. Guidelines of the Echocardiographic Assessment of the Right Heart in Adults: A Report from the American Society of Echocardiography. Endorsed by the European Association of Echocardiography, a registered branch of the European Society of Cardiology, and the Canadian Society of Echocardiography. J Am Soc Echocardiogr 2010;23:685-713.

15. Lang RM, Bierig M, Devereux RB, et al. Recommendations for Chamber Quantification: A Report from the American Society of Echocardiography's Guidelines and Standards Committee and the Chamber Quantification Writing Group, Developed in Conjuction with the European Association of Echocardiography, a Branch of European Society of Cardiology. J Am Soc Echocardiogr 2005;18:1440-63.

16. Nageh MF, Kopelen HA, Zoghbi WA, Quiñones MA, Nagueh SF. Estimation of mean right atrial pressure using tissue Doppler imaging. Am J Cardiol 1999;84:1448-51.

17. Young DB. Control of Cardiac Output. Chapter 2 Venous Return. San Rafael (CA): Morgan -Claypool Life Sciences. 2010. https://www.ncbi. nlm.nih.gov/books/NBK54476

18. Nagueh SF, Middleton KJ, Kopelen HA, Zoghbi WA, Quinones MA. Doppler tissue imaging: A noninvasive technique for evaluation of left ventricular relaxation and estimation of filling pressures. J Am Coll Cardiol 1997;30:1527-33

19. Yu CM, Sanderson JE, Marwick TH, Oh JK. Tissue Doppler imaging a new prognosticator for cardiovascular diseases. J Am Coll Cardiol 2007:49:1903-14

20. Meldumi RM, Suri RM, Bruce CJ, et al. Elevated Left Ventricular End Diastolic Pressure Predicts New-onset Atrial Fibrillation Following Cardiac Surgery: A Community-based Study Circulation 2009;120(Suppl 18):395.

21. Yamamoto T, Oki T, Yamada H, et al. Prognostic value of the atrial systolic mitral annular motion velocity in patients with left ventricular systolic dysfunction. J Am Soc Echocardiogr 2003;16:333-9.

22. Hillis GS, Ujino K, Mulvagh SL, Hagen ME, Oh JK. Echocardiographic indices of increased left ventricular filling pressure and dilation after acute myocardial infarction. J Am Soc Echocardiogr 2006;19:450-6.

23. Forfia PR, Fisher MR, Mathai SC, et al. Tricuspid annular displacement predicts survival in pulmonary hypertension. Am J Respir Crit Care Med 2006;174:1034-41.

24. Oketona OA, Balogun MO, Akintomide AO, et al. Right ventricular systolic function in hypertensive heart failure. Vasc Health Risk Manag 2017;13:353-60.
25. Modin D, Møgelvang R, Andersen DM, Biering-Sørensen T. Right Ventricular Function Evaluated by Tricuspid Annular Plane Systolic Excursion Predicts Cardiovascular Death in the General Population. J Am Heart Assoc 2019;8:e012197.

26. Guazzi M, Bandera F, Pelissero G, et al. Tricuspid annular plane systolic excursion and pulmonary arterial systolic pressure relationship in heart failure: an index of right ventricular contractile function and prognosis. Am J Physiol Heart Circ Physiol 2013;305:1373-81.

27. Pranvera Ibrahimi, Afrim Poniku, Violeta Hysenaj, et al. Predictors of exercise capacity in heart failure. International Cardiovascular Forum Journal 2013:1.

28. Lorell BH, Carabello BA. Left ventricular hypertrophy: pathogenesis, detection, and prognosis. Circulation 2000;102:470-9.

29. de Simone G, Gottdiener JS, Chinali M, Maurer MS. Left ventricular mass predicts heart failure not related to previous myocardial infarction: the Cardiovascular Health Study. Eur Heart J 2008;29:741-7.

30. Greenberg B, Chatterjee K, Parmley WW, Werner JA, Holly AN. The influence of left ventricular filling pressure on atrial contribution to cardiac output. Am Heart J 1979;98:742-51.

31. Owen CG, Newsom RS, Rudnicka AR, Barman SA, Woodward EG, Ellis TJ. Diabetes and the Tortuosity of Vessels of the Bulbar Conjunctiva. Ophthalmology 2008;115:27-32.

32. Magder S. Volume and its relationship to cardiac output and venous return. Crit Care 2016;20:271.

33. Rothe CF. Reflex control of veins and vascular capacitance. Physiol Rev 1983;63:1281-95.

34. Hahn C, Schwartz MA. Mechanotransduction in vascular physiology and atherogenesis. Nat Rev Mol Cell Biol 2009;10:53-62.

35. Feldner A, Otto H, Rewerk S, Hecker M, Korff T. Experimental hypertension triggers varicosis-like maladaptive venous remodeling through activator protein-1. FASEB J 2011;25:3613-21

36. Gomez I, Benyahia C, Le Dall J, et al. Absence of inflammatory conditions in human varicose saphenous veins. Inflamm Res 2013;62:299-308.

37. Spinale FG, Coker ML, Heung LJ, et al. A matrix metalloproteinase induction/activation system exists in the human left ventricular myocardium and is upregulated in heart failure. Circulation 2000;102:1944-9.

38. Reinhardt D, Sigusch HH, Hensse J, Tyagi SC, Körfer R, Figulla HR Cardiac remodelling in end stage heart failure: upregulation of matrix metalloproteinase (MMP) irrespective of the underlying disease, and evidence for a direct inhibitory effect of ACE inhibitors on MMP. Heart 2002;88:525-30

39. Jacob MP, Cazaubon M, Scemama A, et al. Plasma matrix metalloproteinase -9 as a marker of blood stasis invaricose veins. Circulation 2002;106:535-8. 